\title{
DESENVOLVIMENTO DE UMA BIBLIOTECA DE JOGOS PARA APRENDIZAGEM EM LOGÍSTICA E TRANSPORTE
}

\section{Alexandre Akira Kariatsumari ${ }^{\star}$ José Carlos Redaelli, Orlando Fontes Lima Jr.}

\section{Resumo}

Um tópico pouco difundido mundialmente, porém com grande potencial didático, principalmente para alunos que compõem a geração milênio, é o uso de jogos orientados ao ensino e aprendizagem. Esta pesquisa visa fazer um levantamento de jogos em artigos e universidades, nacionais e internacionais que são utilizados como ferramentas de aprendizagem em logística e transportes, categorizá-los e criar um banco de dados. Isto possibilitará a geração da biblioteca de jogos educacionais para os professores da Faculdade de Engenharia Civil, Arquitetura e Urbanismo (FEC), contendo novas ferramentas que visam o aperfeiçoamento do ensino e aprendizagem em logística e transporte. Este trabalho está inserido no Projeto Ensino e Aprendizagem do Laboratório de Aprendizagem em Logística e Transportes (LALT).

\section{Palavras-chave:}

Jogos, tecnologia educacional, logística.

\section{Introdução}

O uso de jogos educacionais como ferramentas de ensino é uma aposta promissora devido as suas características de ensinar e reforçar não apenas o conhecimento, mas também importantes habilidades como solução de problemas, trabalho em equipe e comunicação.

O objetivo do projeto é pesquisar jogos educacionais que abordem os temas de logística e transportes, e catalogá-los de forma a criar um acervo de jogos e trazê-los para ficar à disposição do LALT. Os jogos serão analisados em diversas características e organizados de acordo com os resultados da análise de modo semelhante a uma biblioteca. Por fim, será elaborado um banco de dados sobre os jogos estudados onde estarão explicadas todas as características analisadas e dados do jogo para quem desejar utilizá-lo.

\section{Resultados e Discussão}

Os jogos estudados foram os seguintes: Desafiando a Produção, Linha de Balanço, Jogo do Andaime, Equipment Replacement Game, The Imitation Game, The Muck Game, Beer Game, Sustainable Water and Sanitation Management, Parede Game, Jogo do TECON, Fábrica de Casas de LEGO, OOPS Game, SOLOG, Jogo do TRC, Jogo de Logística Empresarial no Tabuleiro, Systematic Layout Planning Game, $5 S$ e Maroon White Game.

Foi desenvolvida uma análise SWOT com esses jogos. Nesta análise, foram adicionados três tópicos para categorizar e comparar os jogos. Estes foram: onde, data e nota relativa à importância do tema.

Em seguida iniciou-se o processo de elaboração da biblioteca. Para os jogos que necessitam de materiais físicos, foram elaborados um layout de tabuleiro e cartas mantendo um padrão para dar uniformidade e identidade ao material, e enviados para uma impressão e assim poder armazenar o jogo no LALT. Para os jogos digitais, foi necessário contactar os autores dos jogos para que enviassem o arquivo do jogo.
Figura 1. Logo da Biblioteca de jogos.

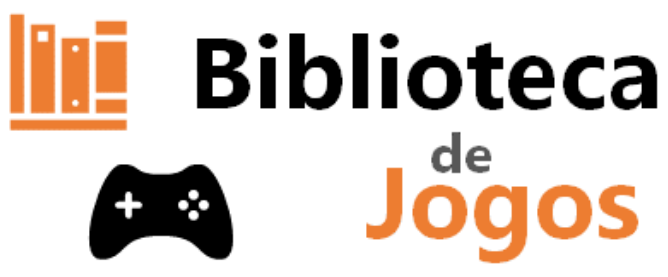

\section{Conclusões}

Ao final do projeto, foram adquiridos diversos jogos que possuem grande capacidade para aprimorarem o ensino de engenharia civil da UNICAMP. Concluiu-se que a biblioteca de jogos trará motivação extra para os professores diversificarem suas aulas, e estará pronta para ser utilizada e colocada em prática.

\section{Agradecimentos}

Agradecimento ao co-orientador José Carlos, com quem aprendi muito, tanto academicamente como pessoalmente neste período. Ao prof. Orlando Fontes por ter dado oportunidade e confiança de realizar esta pesquisa, e me direcionar ao caminho correto no projeto. À Camila Gigov, que esteve presente me apoiando durante todo o período. À equipe do LALT pelo suporte e estrutura em projetos acadêmicos. 